\title{
Active Magnetic Bearing as a Force Measurement System
}

\author{
Prince Owusu-Ansah, Hu Yefa, and Rhoda Afriyie Mensah
}

\begin{abstract}
This article presents active magnetic bearing as a force measurement system. Identification of the dynamic behavior of the rotating machinery have been studied. The main technique was to excite the system under consideration in a time, frequency domain using MATLAB program which runs on a personal computer. Experimental results of the free-free rotor model for the first three elastic mode shapes is presented. The rotor was excited with stepped sine excitation from 20 to $800 \mathrm{~Hz}$, with the sinusoidal excitation exciting the rotor at each bearing ends. The frequency response function at AMB1 which demonstrated the growth of gyroscopic effect was measured at four different speeds $(0,2000,4000,60001 / \mathrm{min})$. The gyroscopic split was obvious at a speed of $53.2 \mathrm{~Hz}$ for the first Eigen frequency at a speed of $60001 / \mathrm{min}$. Calculated eigen frequencies values which was measured showed small difference between them which goes to confirm the suitability of AMBs as a force measurement system.
\end{abstract}

Index Terms-Force measurement, natural frequency, rotor, identification.

\section{INTRODUCTION}

The use of Rotor dynamic methods for performing simulations in high speed rotating components using finite element analysis are readily available in recent times [1], [2]. High speed industrial rotating machine parts such as the flywheel rotor, turbines, propeller shafts, magnetic bearings are very important when studying the behaviors of gyroscopic effects, damping, moment of inertia, unbalance, fluid structure and its interrelated forces [3], [4].

Rotor dynamic system has the capabilities of identifying modal parameters such as damped and undamped values, vibration frequency and modes shapes [5], [6]. Most often than not these powerful tools are able to work without encountering any difficulties, usually the only consideration factor is to ensure that the correct input data is fed into the system [7], [8].

Identification techniques and procedures have been used in many application to determine modal parameters of rotor system with and without rotation involving rotor dynamic coefficients, damping, stiffness and inertia as in seals and bearings [9].

\section{DYNAMIC CHARACTERISTICS OF ROTATING SYSTEMS}

Generally, considering the equation of multiple-degrees-of-freedom systems.

Manuscript received June 6, 2015; revised June 2, 2016

Prince Owusu-Ansah is with School of Mechanical and Electronic Engineering, Wuhan University of Technology, P.R. China (e-mail: Prinosah1990@yahoo.co.uk).

$$
[\mathrm{M}]\{\ddot{D}\}+[\mathrm{C}]\{\dot{D}\}+[\mathrm{K}]\{\mathrm{D}\}=F
$$

where $[D]=$ displacements vector for a problem of $\mathrm{n}$ degree of freedom donated by $[\mathrm{D} i], i=1,2 \ldots n . ;[\mathrm{F}]=$ external forces vector; $[\mathrm{M}]=$ mass matrix; $[\mathrm{C}]=$ damping matrix; and $[\mathrm{K}]$ is the stiffness matrix. Eq. 1 represents the governing equation of a transient structural simulation. The right hand side of the equation is the external force $[\mathrm{F}]$ and the first item of the left hand side of the equation, is inertia force, is damping force, and is the elastic force.

When analyzing the free vibration of a body there is no involvement of the external force $[\mathrm{F}]$. So, Eq.1 becomes

$$
[\mathrm{M}]\{\ddot{\mathrm{D}}\}+[C]\{\dot{\mathrm{D}}\}+[\mathrm{K}]\{\mathrm{D}\}=0
$$

\section{FORCE MEASUREMENT TECHNIQUE}

This process of measurement is to excite the rotor dynamic system by artificial or kinematic excitation, this ensures that the input and output signals are measured, and the process function are then used during parameters estimation which is refer to us Identification.

On the other hand when the dynamic model is known and the parameters are not identified, this process is refer as identification of parameters [10], [11]. The dynamic characteristic can be calculated by means of known input and output relation using time or frequency domain functions.

In principle force measurements in AMBs consists basically of two methods [9]-[11]. In order to be obtain good measurement results, the procedure of force measurement needs to be very accurate as much as possible. The first method which is more accurate is based on the direct measurement of the magnetic flux density, in this instance the flux measurement method of the pole is calculated by,

$$
\mathrm{F}=\frac{B^{2} A}{\mu_{0}}
$$

where $\mu_{\mathrm{o}}$ is the permeability coefficient and $\mathrm{A}$ the pole surface area.

However the main disadvantage associated with this method is the hall sensors inserted in the magnetic circuit which measures the magnetic flux. In this method the hall sensor can either be fixed at the north pole or in some cases all the poles, compared to the later in which a network computing is required in order to determine the unmeasured fluxes present at the south poles. The direct force measurement needs no further approximation or assumptions and is a very accurate method in that the method is not influenced by non-linear effects such as amplifier saturation. The installation of hardware components, ampere windings ensures and justifies a good quality measurement results.

The second technique requires coil current and the rotor 
displacement which is often described as the i-s-method, the advantage of this method is that it requires no additional hard ware, but has the disadvantage that the relation gets significantly nonlinear in the range of maximum force, another disadvantage associated with this method is that saturation, hysteresis and eddy current effects cannot be taken into account with this method.

\section{MATERIAL AND METHODS}

At first, the model structure for the system which is under investigation was established in these case the flywheel rotor with its linear model described by differential equation with constant parameters which is based on the input-output functions as well as impulse response functions (time domain) or frequency response function.

The test rig in Fig. 2 describe the system layout of a rotor setup. The rotor is located between two active magnetic bearings levitating the rotor. In addition are two mechanical seals which seals the upper part of the system. The fault free rotor dynamic system which is being modeled is inserted into the main setup, as shown in Fig. 2 with all the active magnetic bearing and its related components in place, the system is made to go through a series of cycle rotation and operation whiles using measured compliance frequency response function techniques, corresponding measured values are taken. These values are carefully observed for the full length operation of the rotor system. The compliance functions changes of the rotor are noticed, studied and compared with theoretical values and any changes noticed are attributed to the wear which has occurred in the system. In this technique the measured compliance function is a feature of the fault diagnosis and the change of that feature represents a symptom of the fault in the system.

Lastly in the process of parameter estimation the functions of the model are fitted to the corresponding measured functions by varying the modal or physical parameters within the model using signal processors and the corresponding values measured and compared with existing theoretical data for comparison, analysis and conclusions to be drawn

\section{MODAL ANALYSiS}

Modal testing methods for non-rotating structures are well developed for the analysis of dynamic behavior for rotating machinery. To verify the capability of the AMB as a force measurement system for modal analysis, a test rig was built which allows investigation of several rotor dynamic effects to be studied. In Fig. 2, an experimental setup is shown, at the center is a flexible rotor structure with shaft (S) including the AMB-bushes (BS) and the disk (D).

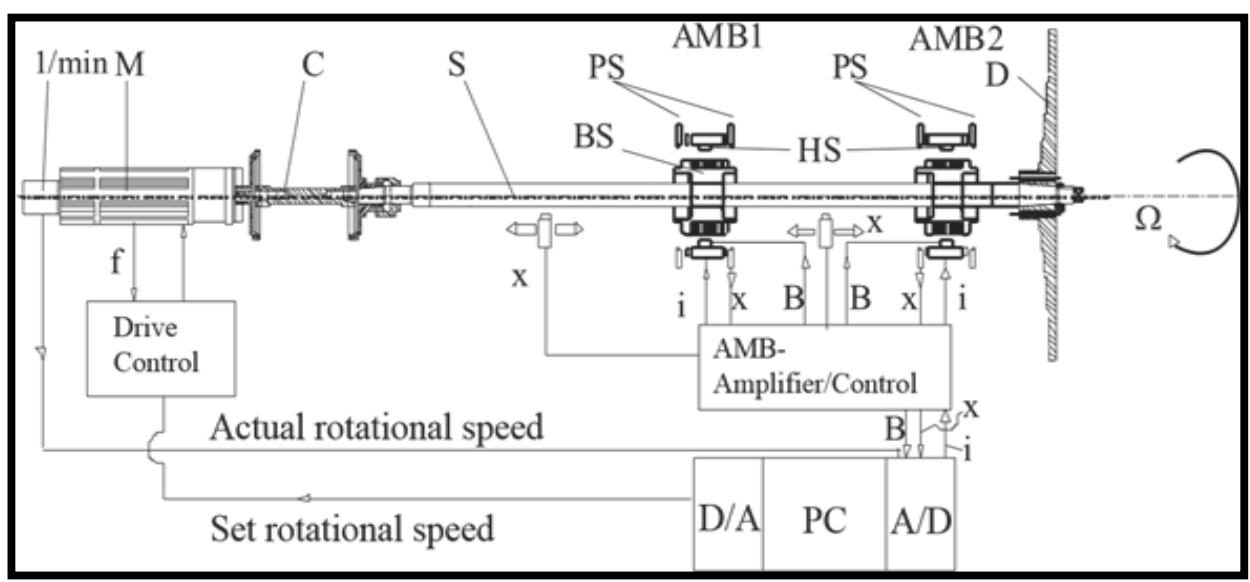

Fig. 2. Experimental setup of a test rig.

\begin{tabular}{cccc} 
& \multicolumn{3}{c}{ TABLE I: ROTOR SPECIFICATIONS } \\
\hline Shaft & & Parameters \\
Length & $1250[\mathrm{~mm}]$ & \\
Diameter & & $47[\mathrm{~mm}]$ & \\
Young's modulus & & $1.96 \times 10^{11}\left[\mathrm{~N} / \mathrm{m}^{2}\right]$ & \\
Density & & $7850 \mathrm{~kg} / \mathrm{m}^{3}$ & \\
& & Polar inertia $\left[\mathrm{kg} \mathrm{m}^{2}\right]$ & Diametrical inertia $\left[\mathrm{kg} \mathrm{m}^{2}\right]$ \\
\hline Disk & mass $[\mathrm{kg}]$ & $0.59\left[\mathrm{~kg} \mathrm{~m}^{2}\right]$ & $0.342\left[\mathrm{kgm}^{2}\right]$ \\
\hline Rigid Disk & $25.57[\mathrm{~kg}]$ & $0.57\left[\mathrm{~kg} \mathrm{~m}^{2}\right]$ & $0.343\left[\mathrm{kgm}^{2}\right]$ \\
\hline Flexible Disk & $25.14[\mathrm{~kg}]$ & & \\
\hline
\end{tabular}

The rotor which is driven by a $2 \mathrm{KW}$ AC servo motor through couple $\mathrm{C}$ with its physical parameters and specifications are shown in Table I. The main membrane coupling which works like a cardiac joint allows the shaft ends to move in a radial displacement directions with defined low stiffness.

The AMBs (AMB1, AMB2) with their Position Sensors (PS) and Hall Effect Sensors are linked to the main PC and controlled by MATLAB. In addition the movable displacement sensors along the main shaft allows detection of the mode shapes of the structure to be done.

\section{EXPERIMENTAL RESULTS AND DISCUSSIONS}

The experimental results of the free-free rotor model is presented. The first three elastic mode shape of the rotor shows that each shape has a node closer to the disk position, the first two mode indicated good observability of the AMB 
sensor position. The third mode was not controllable by AMB 2, which was due to the node at the middle of AMB 2 which has to be taken into account when exciting the rotor structure, as such in this experiment there was no need to excite this mode through AMB 2. The calculated results were obtained for the rotor dynamic behavior using Finite Element Program which has been especially adapted for the rotor dynamic system. The shaft was divided into several beam elements involving additional disk element.

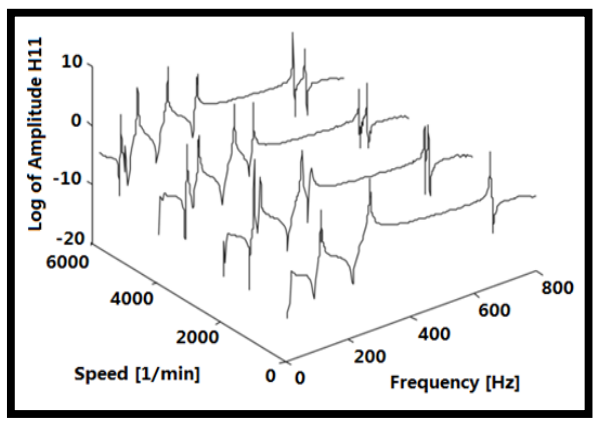

Fig. 3. Three dimensional plot of frequency response for test rig.

In Fig. 3 the frequency response function $H_{11}$ at AMB 1 in the vertical direction is shown. To demonstrate the growth of the gyroscopic effects, the frequency response function was measured at four different speeds $(0,2000,4000,6000$ $1 / \min )$.
The frequency response function of the rotor was measured, the rotor was excited with stepped sine excitation from 20 to $800 \mathrm{~Hz}$.

The sinusoidal excitation excites the rotor at each bearing, one after the other in a horizontal and vertical direction. At each individual test, all forces acting on the rotor were measured. The gyroscopic split is obvious at higher speeds which is $53.2 \mathrm{~Hz}$ for the first Eigen frequency at $60001 / \mathrm{min}$ as shown in Fig. 4.

Lastly in the process of parameter estimation of the model are measured functions by varying the modal and the physical parameters within the model. The iterative procedure for improving the system is therefore interrupted when the correlation for the model and the measurement results were acceptable as indicated in Table II.

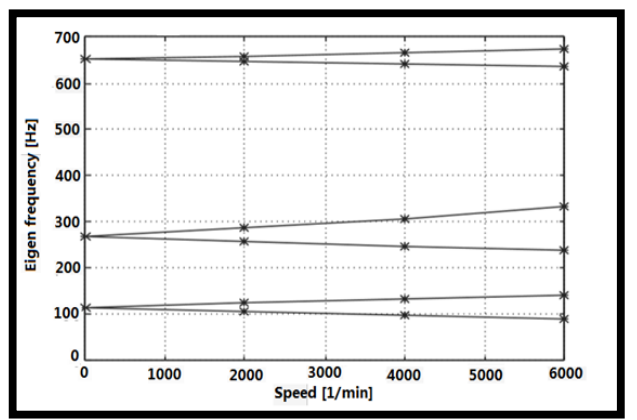

Fig. 4. Campbell diagram of the Test rig.

TABLE II: COMPARISON OF MEASURED AND CALCULATED EIGEN FREQUENCIES

\begin{tabular}{|c|c|c|c|c|}
\hline Frequency & \multicolumn{2}{|c|}{$0[1 / \mathrm{min}]$} & \multicolumn{2}{c|}{$3000[1 / \mathrm{min}]$} \\
\hline & Measured & Calculated & Measured & Calculated \\
\hline 1F $(\mathrm{Hz})$ & 57.4 & 57.1 & 68.1 & 67.9 \\
\hline 1B $(\mathrm{Hz})$ & 57.4 & 57.1 & 41.3 & 41.1 \\
\hline 2F $(\mathrm{Hz})$ & 132.0 & 131.7 & 163.1 & 163.3 \\
\hline 2B $(\mathrm{Hz})$ & 132.0 & 131.7 & 115.6 & 115.4 \\
\hline 3F $(\mathrm{Hz})$ & 323.4 & 325.2 & 335.1 & 336.5 \\
\hline 3B $(\mathrm{Hz})$ & 323.4 & 325.2 & 316.1 & 317.5 \\
\hline
\end{tabular}

\section{CONCLUSION}

Modelling and simulation has now become an essential tool in the field of mechanical engineering design more especially in the area of rotor dynamic systems and turbomachinery. In such essential area of application, rotor dynamic models only are applied for the dissemination and prediction of dynamic behavior.

It has been well established that modeling and simulation cannot be achieved only by theoretically based procedures and physical laws but often than not it may require experimental techniques such as identification to be able to determine the physical or modal parameters of the rotating structure.

The quality of the calculation in this study has been confirmed with the comparison of calculated and measured Eigenfrequencies which indicates small difference between these two frequencies values, comparing these experimental and calculated values with existing theoretical values confirms that active magnetic bearing (AMB) can be used as a force measurement system for the operation of high speed energy storage rotors without encountering any systematic and operational difficulties.

\section{ACKNOWLEDGEMENTS}

This work was supported by The Natural Science Foundation of China (NO.51275372) and Wuhan High-Tech Development Project Foundation (NO.201110921299) and The Fundamental Research Funds for the Central Universities (Wuhan University of Technology No.2012-IV-036).

\section{REFERENCES}

[1] R. Larsonneur, "A high speed rotor in active magnetic bearings," in Proc. the 3rd International Conference on Rotordynamics, CNRS Lyon, France, 1990.

[2] J. U. Duncombe, "Infrared navigation - Part I: An assessment of feasibility," IEEE Trans. Electron Devices, vol. ED-11, pp. 34-39, Jan. 1959.

[3] E. Knopf and R. Nordmann, "Active magnetic bearings for the identification of dynamic characteristics of fluid bearings," in Proc. 6th International Symposium on Magnetic Bearings, Cambridge, USA, 1998.

[4] J. Ackerman, Sampled Data Control Systems, Springer-Verlag, 1985, pp. 213-217.

[5] E. Knopf and R. Nordmann, "Identification of the dynamic characteristics of turbulent journal bearings using active magnetic," in Proc. 7th International Conference on Vibration in Rotating Machinery, Nottingham, 2000.

[6] D. Childs, Turbomachinery Rotordynamics, Phenomena Modeling, and Analysis, John Wiley \& Sons, 1993. 
[7] M. Aenis and R. Nordmann, "Active magnetic bearings for fault detection in a centrifugal pump," in Proc. $7^{\text {th }}$ International Symposium on Magnetic Bearings, Zurich, Switzerland, 2000.

[8] D. J. Ewins, Modal Testing Theory and Practice, John Wiley\& Sons, 1995.

[9] P. Forch and C. Gahler, "AMB system of rotordynamic experiments, calibration results and control," in Proc. 5th International Symposium on Magnetic Bearings Kanazawa, Japan, 1998, vol. 33, no. 46, pp. 23-26.

[10] C. Gahler, "Rotordynamic testing and control with active magnetic bearings," PhD Thesis, ETH Zurich, Switzerland, 1998.

[11] C. Gahler and P. Forch, "A precise magnetic exciter for rotordynamic experiments," in Proc. The 4th Int ${ }^{e r}$ national Symposium on Magnetic Bearing, Zurich, Switzerland, 1994

Prince Owusu-Ansah is currently a Ph.D Mechatronic third year student at Wuhan University of Technology. He received his B.Sc. and M.Sc. degrees in mechanical engineering from the Kwame Nkrumah University of Technology in Ghana, West Africa between 2007 and 2010 respectively.

Between the periods of 2000 to 2013, he was a lecturer at the Department of Mechanical Engineering at Kumasi Polytechnic, in Ghana West Africa. His research interest includes rotor dynamics, magnetic bearing system, active vibration control, contact dynamics and associated thermal behavio of auxiliary bearings. He is married with four children.
Hu Yefa holds B.Sc. and M.Sc. degrees from the Wuhan University in the People's Republic of china, and his Ph.D degree from the University of Manchester, UK awarded in 1990.

Professor $\mathrm{Hu}$ Yefa is involved in various research projects on active magnetic bearing (AMB) and specialized in the field of control and rotordynamics for high speed rotation. Between the periods of 2005 to 2010 he was the head of the Hubei Digital Key Manufacturing Laboratory at Wuhan University of Technology, China.

Professor $\mathrm{Hu} \mathrm{Ye} \mathrm{Fa}$ can look back to 25 years of involvement into research technology in the field of Mechatronics. He is married with a child.

Rhoda Afriyie Mensah was awarded a Bsc. in mechanical engineering in Ghana at the Kwame Nkrumah University of Technology in June 2012. Currently a third year M.Sc. student of the Automobile Engineering Department at Wuhan University of Technology is a member of the Ghana Institute of Engineers.

Her research interest area includes simulation in internal combustion engines, flywheel energy storage systems design, Interactive robots, magnetic bearing design and mechatronics engineering. 
Mechatronics Engineering 
